\title{
UM OLHAR DIFERENTE SOBRE A BRANCA DE NEVE E OS SETE ANÕES - UM RECURSO DIDÁTICO SOBRE O FUNCIONAMENTO MENTAL $^{1}$
}

\author{
A DIFFERENT VIEW ABOUT THE SNOW WHITE AND THE SEVEN \\ DWARTS : A DIDATIC RESOURSE ABOUT MENTAL FUNCTIONING \\ UNA MIRADA DISTINTA SOBRE BLANCANIEVES Y LOS SIETE ENANOS \\ - UN RECURSO DIDÁCTICO SOBRE EL FUNCIONAMIENTO MENTAL
}

Waldine Viana da Silva ${ }^{2}$ Antonio Carlos Vieira da Silva ${ }^{3}$

\begin{abstract}
RESUMO: Neste estudo enfoca-se os traços de personalidade, procurando ampliar a questāo do funcionamento mental face à riqueza de um trabalho fundamentado em um conto de fadas. Pretendese valorizar o funcionamento mental de cada anāo enquanto personalidade de uma trama emocional, desencadeada pela inveja de uma madrasta com a beleza e a juventude de uma enteada adolescente. Por outro lado, acredita-se, que essa temática possa servir de recurso didático sobre o funcionamento mental, servindo como guia prático, simples e dinâmico para o professor em sala de aula, tanto com alunos de enfermagem, como com alunos de psicologia e medicina, em fase inicial de aprendizagem na especialidade.
\end{abstract}

PALAVRAS-CHAVE: recurso didático, funcionamento mental.

\section{INTRODUÇÃO}

Entender sobre Saúde e Doença Mental depende em grande parte de compreender os processos através dos quais os seres humanos desenvolvem-se emocional e cognitivamente (Kaplan; Sadock, 1986).

No público em geral, principalmente na comunidade universitária, há curiosidade em querer ter acesso aos conhecimentos técnicos da área da Psiquiatria e da Saúde Mental. Ao mesmo tempo, há uma surpresa dos estudantes em se reconhecerem nos estudos sobre Personalidade. Muitas vezes a personalidade de um indivíduo caracteriza-se por um traço ou estilo identificável, relativamente persistente, não importando as circunstâncias. Existem indivíduos que são vistos como esquisitos, diferentes, desconfiados, medrosos, exibicionistas, entre outros. Sabemos que estes traços de personalidade podem ou não interferir na adequação dessas pessoas ao meio ambiente; alguns estão adaptados, outros mostram-se aflitos. Diante da capacidade de modificarem ou não o seu comportamento, bem como dependendo do grau

t Trabalho apresentado no $48^{\circ}$ CBEn em São Paulo em 1996 e no VI Ciclo de Debate sobre o Ensino em Enfermagem Psiquiátrica em Belo Horizonte, novembro de 1998.

${ }^{2}$ Docente da UFPa. Especialista e Mestre pela UFRGS e Doutoranda da Escola de Enfermagem da USP.

${ }^{3}$ Médico pela UFPa. Especialista em Psiquiatria pela UFRGS. Estagiário em Interconsulta Psiquiátrica pela UNIFESP/Escola Paulista de Medicina. 
de sofrimento de cada um, poderão chegar a procurar ajuda de um profissional.

Apesar de existirem interesses em compreender como funciona a Personalidade, eis que tal tema é complexo. Conceituá-la de modo útil e compreensivo é uma difícil missão. $\mathrm{A}$ personalidade é temporal e pertence a cada individuo de modo diferente. De acordo com Taylor (1992), personalidade é "a soma das qualidades físicas e mentais do individuo à medida que interagem de modo caracteristico em seu ambiente".

Evidencia-se, portanto, que para se compreender a Personalidade há necessidade de junção dos dotes biológicos e intelectuais, atributos adquiridos da experiência, suas reações e emoçőes conscientes e inconscientes.

Neste estudo, queremos enfocar os traços de personalidade, procurando ampliar a questão do funcionamento mental, face à riqueza de um trabalho quando se fundamenta em um conto de fadas. Pretende-se valorizar o funcionamento mental de cada Anão, enquanto personalidade, e ao mesmo tempo valorizar a trama emocional desencadeada pela inveja de uma madrasta com a beleza e a juventude de uma enteada adolescente.

Desde a época de sua criação pelos Irmãos Grimm, o conto sobre BRANCA DE NEVE E OS 7 ANÕES causa forte impacto em todos aqueles que dele tomam conhecimento. Walt Disney (1937) chegou a batizar cada um dos 7 anőes com nomes próprios. Tais nomes se instituiram universalmente, levando o conto de fadas para as telas do cinema em um trabalho fantástico, hoje disponivel também em vídeo. Lamentavelmente, a indủstria brasileira, através de uma contribuição negativa de Carlos Imperial, fez um filme de deboche sobre cada Anão e Branca de Neve, em um clima de promiscuidade sexual. Como os contos de fada têm sempre um cunho educacional e também moral, de uma certa forma esse deboche contribuiu com a inclusão da delinqueência, tema que não é absorvido nessa literatura para crianças, em especial.

Hoje, queremos crer que essa temática possa servir de recurso didático sobre funcionamento mental. A presente idéia surgiu de uma série de seminários proferidos pelos autores na cidade de Porto Alegre (RS) e Belém do Pará, onde tiveram agradável acolhida inspirando o presente trabalho. A intençăo é de que seja um guia prático, simples e dinâmico para o professor em sala de aula. A inveja da madrasta de Branca de Neve, querendo colocar obstáculos no crescimento da enteada, são fatores que servem para demonstrar o quanto tal fato pode ser um material patogênico. Ao mesmo tempo, cada Anăo tem uma estrutura de funcionamento bem como uma forma de lidar com Branca de Neve e de interagir com o seu grupo de iguais. Tal detalhamento pode ser útil para alunos de Enfermagem Psiquiátrica, Psicologia e estudantes de Medicina em Psiquiatria como uma situaçăo de aprendizagem numa fase inicial.

\section{COMPLEXIDADE PSICODINÂMICA DA PERSONALIDADE.}

Os conceitos de consciente, pré-consciente e inconsciente, referem-se apenas a um grau de consciência. Os conceitos de Id, Ego e Superego referem-se à organização da mente em estruturas funcionais. Deve-se resistir à tentaçăo de tratar esses conceitos como se eles fossem coisas tangiveis. É importante, contudo, que se tenha uma visăo da complexidade psicodinâmica da personalidade.

No decorrer dos séculos, vários estudiosos, entre eles, filósofos, escritores, artistas e leigos têm se interessado pelo estudo psicodinâmico na compreensăo da conduta humana. Porém, cabe a Freud o mérito desses estudos pois estabeleceu bases cientificas ao suprir a falta de um denominador comum teórico que possibilitasse um sistema organizado de encontro das diferentes observaçőes individualizadas.

Verificou-se que a personalidade implica no nivel de integraçăo mais evoluido e perfeito de todo o existente, de maneira tal que o grau de complexidade alcança nela seu ponto máximo, năo só pelo aparecimento de caracteristicas peculiares únicas como também porque resumem- 
se ou confluem nela todos os niveis e categorias preexistentes na evoluçăo (Kaplan; Sadock, 1986).

A personalidade é dinâmica, quer dizer, cambiante, está submetida a flutuações entre evoluçăo e regressăo e entre integraçăo e dispersăo. As mudanças ou flutuações săo muito variáveis em suas características e em seu grau, mas em condiçőes normais, conservam-se permanentemente a continuidade $e \mathrm{a}$ identidade. A dinâmica da personalidade coexiste com a persistência de sua continuidade e de tal maneira que uma é condiçăo da outra.

Freud (1962) dividiu a personalidade em três setores aos quais chamou Id, Ego e Superego. $\mathrm{O}$ id é a estrutura da mente que contém as forças instintivas. Estas forças permanecem até certo ponto inconscientes, mas exercem uma continua pressão sobre o resto do aparelho mental. Outras estruturas da mente podem ficar em oposição às forças do ld, causando conflitos. Os conflitos do inicio da infância não săo conflitos internos, mas estão entre a mente infantil (id) e forças ambientais.

O Ego é formado principalmente em consequeencia de interações com o ambiente. Ele tem uma funçăo reguladora, controlando o que a pessoa diz e faz e é a parte mais "personalizada" do aparelho mental. O Ego é uma estrutura mental que permanece mais próxima da realidade. Uma vez tendo se diferenciado a partir do id, o ego freqüentemente entra em conflito com este. $\mathrm{O}$ ego usa a ansiedade como um aviso e uma arma em seu conflito com as forças do Id. A ansiedade domina os impulsos instintivos e reúne toda a personalidade em linha para tomar as providências adequadas.

O Superego corresponde em grande parte ao termo leigo "consciência". Ele envolve atividades mentais que podem ser conscientes, pré-conscientes ou inconscientes e é formado por influência dos pais. Sentimentos de culpa, vergonha e ódio podem ser evocados pelo Superego. As forças do superego estăo geralmente em oposiçăo às do Id, embora nem sempre isso ocorra.

A maioria dos conflitos id e ego (conflitos neuróticos) têm lugar abaixo do limiar da consciência. $\mathrm{O}$ individuo vivencia os efeitos do conflito, mas permanece ignorante do real significado daquilo que está ocorrendo dentro de si.

\section{ESTRUTURA DA CONDUTA.}

Para fins didáticos é importante ressaltar os significados de dois conjuntos de termos: funcional e orgânico e neurótico e psicótico.

Segundo Kaplan; Sadock (1986) uma doença orgânica é aquela cuja etiologia envolve necessariamente uma alteraçăo mórbida na estrutura.

Uma doença funcional é aquela cuja etiologia năo envolve necessariamente alterações estruturais e cujos sintomas se baseiam em respostas năo sadias do organismo. Exemplo de uma doença desse tipo, é a gagueira; em via de regra, năo se demonstra nenhuma alteraçăo estrutural no aparelho da fala.

No segundo conjunto de termos, neurótico e psicótico, o problema é muito mais complexo. Procurar-se-á descrevê-las a grosso modo para um melhor entendimento. A expressăo neurose corresponde ao termo leigo "nervosismo" e psicose amplamente utilizado como "insanidade"; vale a pena ressaltar que se perceba que esses termos năo são mais do que aproximações.

\section{FUNCIONAMENTO MENTAL E ESTILO DE VIDA DOS SETE ANÕES.}

Quando olhamos detidamente a figura dos 7 Anões como batizados por Walt Disney, percebemos que cada um apresenta um tipo de funcionamento mental. A deficiência de DUNGA, 
a Alegria do FELIZ, a organizaçăo do MESTRE, o jeito brigão do ZANGADO, os problemas somáticos do ATCHIM, a apatia do SONECA e a teatralidade do DENGOSO.

$\mathrm{O}$ que se propōe como recurso didático é uma caricatura onde se exagera o estilo de cada Anão, até adoecê-lo, no sentido de se aumentar qualitativamente, de forma gradual, os elementos do funcionamento mental.

\section{FUNCIONAMENTO MENTAL OBSESSIVO}

A caracteristica desse funcionamento é a conduta ritualizada. "O ritual aparece ou configura-se quando se estereotipa a forma com a qual impede-se o perigo do objeto persecutório e perigoso, seja anulando-o magicamente ou controlando uma distância ótima entre o objeto mau e bom. O ritual pode consistir numa companhia estereotipada, num objeto que serve de amuleto ou num determinado cerimonial. Nesse controle, a ordem serve também como ritual estereotipado." (Bleger, 1989).

Para exemplificar o funcionamento mental obsessivo, vamos nos valer da figura do ANÃO MESTRE. Mostra-se organizado, sempre querendo colocar tudo em ordem, preocupado com a limpeza, buscando um papel de liderança onde cuida dos demais. Vive intensamente em busca da perfeiçăo. Convive com uma contradição: busca ser perfeito, mas é quem sempre está errando, trocando palavras como se observa no filme de Walt Disney (troca mina por tina, santo por canto, etc...).

\section{FUNCIONAMENTO MENTAL PARANOIDE}

Nesse funcionamento, "o caracteristico é que o sujeito acusa, identifica ou vivencia no mundo externo, um objeto ou objetos persecutórios ou perigosos, que podem irromper, pondo em perigo o equilibrio ou a integridade do seu Ego, quer dizer, o sujeito sente-se ameaçado por perigos que provêm do exterior". (Bleger, 1989).

Para exemplificar o funcionamento mental paranóide, vamos nos valer da figura do ANÃO ZANGADO. Mostra-se desconfiado, brigão, provocativo. Sempre acha que os demais estão contra ele. Năo aceita ajuda, acreditando que querem Ihe prejudicar. Está sempre em um papel defensivo como se algo de ruim fosse ocorrer repentinamente.

\section{FUNCIONAMENTO MENTAL HIPOMANIACO}

O funcionamento hipomaniaco "caracteriza-se por um ritmo especial de aproximaçăo e afastamento alternado, à velocidade, com o qual consegue-se o controle e a imobilização do objeto perigoso" (BLEGER, 1989).

Para exemplificar o funcionamento mental hipomaniaco, vamos nos valer da figura do ANĀO FELIZ. Mostra-se alegre, sempre risonho, falante, tendendo à euforia. Envolve-se em múltiplas atividades, inquieto, sempre com ar triunfante. É o oposto da tristeza e da depressăo. Gosta de festas, de ambientes alegres e usa roupas coloridas.

\section{FUNCIONAMENTO MENTAL DEPRESSIVO}

Nesse, "o caracteristico da conduta de estrutura depressiva é o seu aparecimento quando se perdeu ou destruiu um objeto querido tanto como quando se corre risco de perdê-lo ou destrui-lo" (Bleger, 1989).

Para exemplificar o funcionamento mental depressivo, vamos nos valer da figura do ANÃO SONECA. Mostra-se triste, nunca sorri, dorminhoco, vagaroso; quieto, sempre com ar de perdedor. É o oposto da alegria e da euforia. Gosta de se isolar, de ambientes gélidos e usa roupas descoloridas.

\section{FUNCIONAMENTO MENTAL HISTÉRICO}

Este, caracteriza-se, fundamentalmente, "por uma conduta que tem a aparência de 
representação, que, em casos extremos, pode chegar a uma verdadeira teatralidade. Essa aparência de representaçăo deve-se a que a personalidade acha-se dissociada e em parte alheia à conduta, que, por isso mesmo, tem um caráter de ficção ou de representação. A relação com o mundo exterior é aparentemente fácil e fluida e apresenta sempre, em maior ou menor grau, um caráter de seduçäo" (Bleger, 1989).

Para exemplificar o funcionamento mental histérico, vamos nos valer da figura do ANÄO DENGOSO. Mostra-se regressivo, imaturo, teatral, sedutor. Tem um ar carente, desprotegido, buscando ser mimado. Não quer amadurecer, procurando ser uma eterna criança. Com esse jeito, não gosta de ser contrariado, podendo ficar exaltado com crises onde busca um público para apreciá-lo. Emocionalmente é superficial, tratando as pessoas como se já tivesse intimidade com as mesmas.

\section{FUNCIONAMENTO MENTAL CONVERSIVO}

"Psicologicamente, as conversőes devem ser explicadas com base no controle do aparelho sensorial e motor pelo Ego. No caso dos distủrbios sensoriais, o ego recusa acesso à consciência de certos dados sensoriais vindos de fora; no caso das interferências na função motora, o ego bloqueia o desejo consciente de essa função ativar o aparelho motor. É importante que se perceba que esta atividade é realizada abaixo do limiar da consciência" (Kaplan; Sadock, 1986).

Para exemplificar o funcionamento mental conversivo, vamos nos valer da figura do ANÃO ATCHIM. Mostra um funcionamento como se o perseguidor estivesse dentro dele mesmo, agora no seu corpo. Ora acredita que sofre do figado, do estômago, do coração, e assim por diante. Sempre com queixas orgânicas, somatiza os seus conflitos psíquicos. É oportuno que seja examinado do ponto de vista médico, para excluir a realidade de uma patologia orgânica. De forma irônica, podemos dizer que ATCHIM poderia ter alguma rinite alérgica pelo fato de trabalhar com o ouro, em uma mina, o que deveria ser um exame otorrinolaringológico.

\section{FUNCIONAMENTO MENTAL COM DÉFICIT INTELECTUAL}

Nesse, o característico é o desenvolvimento motor lento e pobre, a fala limitada e ocasionalmente uma total ausência de comunicação (Kaplan; Sadock, 1986).

Para exemplificar o funcionamento mental com déficit intelectual, vamos nos valer da figura do ANÃO DUNGA. São pessoas com o quociente de inteligência (Q.I.) abaixo dos niveis de normalidade, com dificuldades para dar recados, executar tarefas simples, sendo conhecidas como tolas e bobas. Quando muito, conseguem profissões que pouco exigem do seu intelecto. Às vezes, além do déficit intelectual, ainda apresentam algum problema orgânico (mudo, surdo, etc...), com origens em partos difíceis.

\section{CONSIDERAÇÕES FINAIS}

Temos consciência de estarmos exagerando os traços de personalidade dos Anర̃ezinhos. É como se pedissemos uma licença pedagógica para os contos de fadas visando ilustrar um tema dificil como o é quando tratamos a respeito das Personalidades. O estudo sobre o funcionamento mental foi abordado de um ponto de vista postural, cultural e comportamental, enquanto é reconhecido o impacto que esse estudo tem sobre o iniciante do curso de Enfermagem, Psicologia e Medicina. Acredita-se, também baseado em uma experiência anterior do uso de tal material didático, que fica mais fácil para os estudantes compreenderem o próprio comportamento e o de outras pessoas com auxílio desse referencial. De uma forma lúdica, sendo convocados para o terreno mágico do conto-de-fadas, reavivando a própria infância, podem olhar também os traços de personalidade sem o peso do diagnóstico psiquiátrico. Dessa forma, 
năo incorrem no erro de se auto-diagnosticarem ou de quererem diagnosticar a outren, de uma forma perversa, atribuindo doenças mentais, por exemplo.

Por outro lado, acredita-se que o método didático constrói-se, isto quer dizer que tanto 0 conhecimento como os meios instrumentais para obtê-lo são mutáveis e constituem em sua totalidade um processo muito complexo, que fica distante de ser linear e unidirecional.

Năo conseguimos atingir todos os tipos de Personalidade, contudo săo enfocados os principais tipos de funcionamento. Poderiamos acrescentar que o FUNCIONAMENTO MENTAL ANTI-SOCIAL poderia ser do Anăozinho Delinqũente - aquele que foi caracterizado no filme brasileiro onde foi valorizada uma promiscuidade sexual com Branca de Neve. Nos dias de hoje, face $a$ assaltos, violência, consumo de drogas, poderiamos dizer que o Anãozinho

Delinqüente estaria mais preocupado em vender o ouro da mina para conseguir objetivos antisociais.

Supomos que este método ora proposto oferece aos professores mais um recurso para proporcionar conhecimentos, habilidades e atitudes no território psicológico do ser humano.

ABSTRACT: In this study we emphasise the personality caractheristics, tryingto amplify the mental functioning matter facing the richness of a work based on a tale. We aim to worth the mental functioning of each dwarf as a personality envolved on na emocional drama, exploded by the jelousy of the stepmother about the youth and beauty teeanage stepdaugther. On the other hand, we expect this theme can be used as didatic resourse about the mental functioning, serving as a practical, simple and dinamic guide for the professor in classroom, as for Psychiatric Nursing as for Medicine ones, specializing on Psychiatry, in their initial learnig phase.

KEYWORDS: didatic resourses, mental fuctioning.

RESUMEN: En ese estudio se enfocan los rasgos de la personalidad buscando ampliar la cuestión del funcionamiento mental frente a la riqueza de un trabajo que está fundamentado en un cuento de hadas. Se pretende valorar el funcionamiento mental de cada enano, en tanto personalidad de una trama emocional desencadenada por la envidia de una madrastra con la belleza y la juventud de una hijastra adolescente. Por otro lado, se cree que esa temática pueda servir de recurso didáctico sobre el funcionamiento mental, para servir como guia práctico, simple y dinámico para el profesor en clase, tanto con alumnos de enfermeria, como con alumnos de psicologia y medicina a comienzos del aprendizaje en la especialidad.

PALABRAS CLAVE: recurso didáctico, funcionamiento mental.

\section{REFERÊNCIAS BIBLIOGRÁFICAS}

BLEGER, J. Psicologia da Conduta. 2. ed., Porto Alegre: Artes Médicas, 1989.

FREUD, S. The Ego and the Id. New York: WW Norton \& Co. 1962.

KAPLAN, H.I.; SADOCK, B.J. Compêndio de Psiquiatria Dinâmica. Porto Alegre: Artes Médicas, 1986.

TAYLOR, C.M. Fundamentos de Enfermagem Psiquiátrica, de Mereness. 13. ed. Artes Médicas: Porto Alegre, 1992. 